\title{
Older adults' networks and public care receipt: Do partners and adult children substitute for unskilled public care?
}

Article in Ageing and Society · November 2013

DOI: $10.1017 /$ S0144686X13000469

CITATIONS

5

4 authors:

\section{N. Schenk}

Erasmus University Rotterdam

13 PUBLICATIONS 111 CITATIONS

SEE PROFILE

\section{Ineke Maas}

Utrecht University

160 PUBLICATIONS 2,278 CITATIONS

SEE PROFILE
READS

65

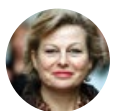

Pearl A. Dykstra

Erasmus University Rotterdam

204 PUBLICATIONS 3,286 CITATIONS

SEE PROFILE

\section{Ruben van Gaalen}

Statistics Netherlands / University of Amster... 30 PUBLICATIONS 372 CITATIONS

SEE PROFILE

Some of the authors of this publication are also working on these related projects: 


\title{
Older adults' networks and public care receipt: do partners and adult children substitute for unskilled public care?
}

\author{
NIELS SCHENK*, PEARL DYKSTRA*, INEKE MAAS $†$ \\ and RUBEN VAN GAALEN
}

\begin{abstract}
This study investigates how (a) the reliance on public care and (b) the type of public care received by older people in the Netherlands depends on the availability of partners and adult children. Older people aged $6_{5}$ years and older were surveyed in the Netherlands Kinship Panel Study at two time-points. Survey results were linked to registry data on public care receipt at the two time-points. Multilevel models revealed that receiving frequent help in the household from children was not associated with public care receipt. Only men having a partner were less likely to receive public care. Further analyses comparing the receipt of skilled and unskilled forms of public care revealed that female partners are especially important in rendering unskilled care unnecessary compared to skilled care. Two arguments may explain our findings. One is that a gender-bias exists in processing public care requests - men are perceived as less able to provide care to their female partners. Another is that men lack the skills, or perceive themselves as lacking the care skills that female partners have. Caution is advised against introducing policy measures that increase pressure on female partners.
\end{abstract}

KEY WORDS - older adults, public care, gendered care, informal care, registry data.

\section{Introduction}

Public expenditure on care for older people has been rising along with the increasing number of senior citizens. Expenditures are expected to rise even more as population ageing continues (European Commission 2012). Attempts to constrain expenditures have largely focused on enabling older people to live independently longer, thereby reducing the costs of

* Department of Sociology, Erasmus University, Rotterdam, The Netherlands.

$\dagger$ Department of Sociology, Utrecht University, The Netherlands.

$\ddagger$ Statistics Netherlands, The Hague, The Netherlands. 
1712 Niels Schenk et al.

institutionalisation. Now that the demands for non-institutionalised care have rapidly increased, and are expected to rise even more, this type of care for older people is under pressure as well. Currently, over 12 per cent of European Union residents are 70 years and older, and this percentage is expected to rise to over 19 in 2035 (Eurostat 2012). Many governments are in the process of redesigning their social protection schemes to ensure that home care remains sustainable and that quality of life for older people is maintained. Projections of future formal care use estimate an increase of 79, 116 and 15 o per cent for Germany, The Netherlands and Spain, respectively (Geerts 2012). To ensure the sustainability of care for older people in the future, policy makers are placing greater emphasis on the role of informal care, voluntary organisations and market care, and less on public care (Organisation for Economic Co-operation and Development 2005; Pavolini and Ranci 2008).

\section{A focus on public care}

With the rise of the welfare state, scholars were at first interested in how expanding welfare services might displace or crowd out family support systems. Contrary to the crowding-out hypothesis, older people receive help from family members even in the most generous welfare systems (e.g. Daatland and Lowenstein 2005; Motel-Klingebiel, Tesch-Römer and Von Kondratowitz 2005). This large body of - mostly European - research suggests that welfare services have not replaced the supportive role of the family. The current re-evaluation of social protection policies in many countries, and the increased emphasis that governments have placed on the role of families in providing care, has led researchers to address the opposite question, namely how informal care diminishes the necessity of home care receipt subsidised by the state (Bolin, Lindgren and Lundborg 2008; Bonsang 2009; Van Houtven and Norton 2004). To be able to scale down state expenditures, it is imperative to know if and under what conditions the receipt of informal care helps overcome the need for care provided by the state.

One of the difficulties in assessing the sparse research evidence is that many studies use formal care rather than state care as their object of study (Bolin, Lindgren and Lundborg 2008; Bonsang 2009; Geerts 201 2). Formal care, which in these studies also includes professional care paid for by recipients or their families, is a much broader category than care subsidised by the state. In fact, self-paid professional care, or market care, is an alternative to care subsidised by the state and is also used as such by policy makers stressing alternatives to state-subsidised care (Organisation for Economic Co-operation and Development 2005). In this study we will not 
consider market care, but specifically address home care for older people subsidised by the state. We refer to this with the term public care.

We aim to answer the following research question: to what extent is the receipt of public care by older people associated with characteristics of the family network and help provided by this network? Our hypotheses pertain to types of family care providers, and their gender. They also specify that patterns differ by types of public care. To answer our research question, we use a combination of survey data on the provision of family care and unique registry data on the receipt of public care by older adults in the Netherlands.

\section{The association between informal and public care}

In the Netherlands public care is only provided when care needs cannot be met by close family, also referred to as the principle of subsidiarity (EspingAndersen 1990; Van Hooren and Becker 2012). The principle of subsidiarity is embodied in the two laws that regulate the provision of care to older adults: the Exceptional Medical Expenses Act (EMEA; Dutch: Algemene Wet Bijzondere Ziektekosten, AWBZ) and the Social Support Act (SSA; Dutch: Wet Maatschappelijke Ondersteuning, WMO). The aim of the EMEA is to provide a general insurance covering the Dutch population against exceptional health-care needs. Among other benefits, EMEA regulates the provision of personal care (e.g. help with washing and dressing), nursing care (e.g. treating wounds and giving injections) and social participation support (e.g. help with mobility issues that would hamper family visits). The provision of household care (e.g. help with cleaning) was dropped from the EMEA provisions with the introduction of the SSA in 2007. The Personal Budget (PB) was introduced in 1995 (Kremer 2006). This $\mathrm{PB}$ enabled EMEA-eligible persons to organise and pay for their own care, including the employment of one's own family members. Information on $\mathrm{PB}$ receipt (about 10 per cent of EMEA expenses go to PB recipients) is not available in Dutch registers and therefore is outside the scope of this paper.

Eligibility for EMEA benefits is determined on the basis of a needs assessment performed by the Centre for Care Assessment (Dutch: Centrum Indicatiestelling Zorg, CIZ). The assessment takes not only disorders and functional limitations into account, but also the personal situation of the person requesting benefits ( $\mathrm{Mol} 2010)$. One of the central concepts in this assessment is 'usual care' (Dutch: gebruikelijkezorg). This concept was launched in 2003 and subsequently modified and formalised (Da Roit 2012). It is defined as "the normal, daily care that nuclear family members or other people who share a household can be expected to provide to one another' (CIZ 2012: 9, authors' translation). Physically and mentally capable 


\section{Niels Schenk et al.}

household members are expected to provide a dependent older adult with social participation support and temporary personal care (i.e. when the need for personal care is expected to last no longer than three months) (CIZ 2012). Household members are expected to provide these forms of informal care, regardless of willingness, religious beliefs, cultural background, conflicts with the dependent household member or conflicting obligations (CIZ 2012; Saraceno and Keck 2008). Nursing care and permanent personal care are not considered to be usual care (CIZ 2012).

With the introduction of the SSA in 2007, government responsibility for the provision of household care was transferred to municipalities. Even though local authorities are free to determine household care eligibility criteria, 85 per cent of all municipalities have introduced the usual care protocol used in EMEA needs assessments in their eligibility policy with regard to household care (Tuynman and Marangos 2010). Physically and mentally capable household members are thus expected to provide household care to a dependent older adult before the municipality steps in.

Given the central role of the usual care concept in the needs assessments for EMEA and SSA benefits, frail older people who share a household in the Netherlands typically have only limited access to lighter forms of public care. They are eligible for public care only when they are unable to purchase care, or when their needs exceed the capabilities of their network. We expect to find reliance on public care only under the condition that the family network does not, or cannot provide the care needed. For that reason we distinguish between types of care that can and those that cannot easily exceed the capacities of the family network. We argue that the likelihood that informal care diminishes the reliance on public care depends on the type of public care and characteristics of the family network.

\section{Types of public care}

Unskilled forms of care are much more likely to be provided by family members than are forms of care requiring professional training (Litwak 1985; Wolff and Kasper 2006). Research clearly shows that the degree to which informal care diminishes the reliance on formal care - the research does not address public care specifically-varies with the type of care needed. With increasing disability levels, family members are less able to provide the required care (Walker, Pratt and Eddy 1995). Bonsang (2009) shows that Europeans who receive informal care have a lower probability of receiving formal care when the type of care they require is unskilled but not when it is skilled. More specifically, receiving formal care in the form of paid domestic help is less likely only when help is received from children and when disability levels are low. At high levels of disability, help received from 
Older adults' networks and public care receipt 1715

children does not lower the probability of receiving formal care. It is unknown whether a similar pattern exists for public care. We hypothesise that the availability of informal care diminishes the receipt of unskilled public care but not that of skilled public care.

\section{Characteristics of the family network}

According to Andersen's (1995) behavioural model, the reliance on public care is dependent, among others, on characteristics of the potential care providers in the family network. In line with this model, scholars have shown that having access to care-givers in and outside the household decreases the need for public care ( $\mathrm{Li}, 200_{5}$; Sundström, Malmberg and Johansson 2006).

Research has also shown that informal care is predominantly performed by female partners living in the household (Walker, Pratt and Eddy 1995) and by daughters living outside the household (Haberkern and Szydklik 2010). Although male partners also take on caring duties when necessary, they do so to a lesser extent than female partners (Arber and Ginn 1995; Noël-Miller 2010). Male partners also perform fewer of the traditionally female domestic tasks compared to their female partners (Campbell and Martin-Matthews 2003). As a consequence, older women with a partner are more dependent on public care than older men with a partner (Katz, Kabeto and Langa 2000; Stoller and Cutler 1992). Apart from theoretical reflections on the gendered welfare state (Knijn and Kremer 1997), we know of no empirical study that investigates the gendered relationship between informal and public care. We hypothesise that male partners will be less likely to delay or diminish the reliance on public care compared to female partners. We also hypothesise that older people who receive household support from their children will be less likely to rely on public care, especially for those who receive this help from daughters. When distinguishing types of public care, we hypothesise that the family will be more able to provide unskilled care compared to skilled care, and that female care-givers are especially able to delay or diminish the use of unskilled public care.

\section{Data and methods}

\section{Registry data and the Netherlands Kinship Panel Study}

For this study, registry data on receipt of care financed by the EMEA over two time-points were linked with survey data, the Netherlands Kinship Panel Study (NKPS). The EMEA provides care for those in need of chronic and continuous care both at home and in institutions. It enables recipients with 


\section{Niels Schenk et al.}

chronic disabilities to continue living independently for as long as possible. The registry contains information for all Dutch residents on the various types of public care received. The NKPS is a panel consisting of 8,160 men and women aged 18-79 years (Dykstra et al. 2005). With a response rate of 45 per cent in the first wave held between 2002 and 2004 , and 76 per cent in the second wave held between 2006 and 2007 , non-response and attrition are higher than in comparable surveys in other Western countries, but comparable to other large family surveys in the Netherlands (De Leeuw and De Heer 2001). Information on EMEA receipt was recorded yearly. If the NKPS survey took place in the second half of the year, we selected information on EMEA receipt from the year after the survey. Information from the same year was selected if the interview took place in the first half of the year.

\section{Respondents}

We used data from two categories of respondents. First, we limited the NKPS sample to those with a reasonable chance of receiving public care, namely respondents aged $65^{-79}$ (the age of sample members was capped at 79 ). Ten per cent of the NKPS respondents belong to this age category in the first wave and responded in the second wave. Older adults who had no (living) children, had children under 18 years old only, died between waves or left the country after wave 1 were dropped from the sample. In the exceptional case that older people had children living in the household, respondents were dropped because the survey had no questions on household help received from co-resident children. The selection criteria resulted in a sample of 232 men and 259 women at the first time-point. Linkage to registry information was done by Statistics Netherlands based on the NKPS respondents' addresses. In the total sample, 94 per cent of respondents did not object to linkage of their information to registry records; of these, 95 per cent were successfully linked.

To expand the sample, we added data on older parents by using information provided by their adult children who participated in the NKPS. Individual records of NKPS respondents younger than $6_{5}$ were linked to their parents by using personal index cards available in the Dutch registry. Personal index cards include the child's and the parent's individual registration numbers, their dates of birth and, if applicable, dates of marriage. Record linkage was successful for 93 per cent of the NKPS children who had a parent living in the Netherlands and resulted in a much larger total sample of 1,231 older men and 1,321 older women at the first time-point. The odds of unsuccessful record linkage were higher for older parents and for parents with few children. 
The measures of the independent variables are thus based on self-reports (older adults) and child-reports (adult offspring with older parents). When older people were the respondents, questions on support exchanges were asked for a maximum of two randomly selected living children (Dykstra et al. 2005). When older people were identified by linking them to the child participating in the NKPS, the random selection of the child is the result of the sampling procedure used in the organisation of the survey. Note that the data have two possible sources of bias. The first is that child-reports are from a randomly selected child (unless the parent has only one child), and that perhaps children other than the selected child provided help to their parents. The self-reports refer to help received from at maximum two children. Again, information is missing on whether children other than the selected offspring are providing help. The other possible source of bias is the success of linkage. Sensitivity analyses running our models on the selfreports and the child-reports separately revealed that using two sources of information did not affect our results (not reported here). Coefficients between the two models did not differ substantively.

\section{Measures}

In our analyses we assume that guidance, e.g. how to organise one's day, and personal care such as dressing, bathing, using the toilet and helping with support stockings are unskilled types of public care. Nursing, such as home visits by a nurse to bandage a wound, give an injection, and treatments such as learning how to walk again after a stroke are skilled types of public care.

The following measures of informal care were used. The first is household help received from a living child. Respondents were asked 'In the last three months, did you \{provide help to mother/father or receive help from random child\} with housework, such as preparing meals, cleaning, fetching groceries, doing the laundry?' Answer categories were either no, once or twice, or several times. Dummy variables measure household help received several times from either a son or daughter. The reference category is not receiving help several times from children. We also indirectly measure the provision of informal care by the partner by creating a dummy variable for whether a partner is present ( $1=$ partner living in household), and another dummy variable for whether this partner is female.

The following control variables were used. Two dummy variables measured high and low levels of education of the older adults, with an intermediate level of education as the reference category. Health was controlled for because it influences the need for public care (Van Houtven and Norton 2004). Health status was measured by asking older people to rate their health on a five-point scale ranging from o, very poor, to 4 , excellent. Since 


\section{Niels Schenk et al.}

more wealthy older people are less dependent on public care because of the option to purchase care (Bonsang 2009), we control for monthly household income. The logarithm of monthly household income measured in euros was taken. Monthly income was derived from income tax records available in the registry. Age of older people was measured in years.

\section{Analyses}

Combining the NKPS with Dutch registry data resulted in a longitudinal dataset that enabled us, contrary to most of the previous literature, to estimate models with public care as the dependent variable, and information from the survey as independent variables. We estimated two models. The first model provides an answer to our research question by using a multilevel logistic model predicting whether or not respondents received any type of public care at any of the two time-points. It thus sheds light on the overall impact of informal care on public care by grouping unskilled and skilled types of public care, and comparing older people who receive some form of public care with those who do not. The first model is based on self-reports only. The second model, also using multilevel logistic regression, predicts for those older people receiving at least some form of public care, the receipt of unskilled types of public care versus skilled types of public care. Coefficients in our second model denote odds of receiving unskilled care versus only skilled care. A result in line with our hypothesis would show that older people who receive public care have lower odds of receiving unskilled care compared to skilled care. The second model is based on both self-reports and child-reports. Unfortunately a measure of health is not included in the second model; the first wave of the NKPS has no child-reports of parental health.

In our multilevel models, the first level corresponds to the two time-points used in our analysis, the second level corresponds to the parents. When using NKPS child-reports, the linkage could result in two parents, namely the mother and father of the NKPS respondent. Our third level corrects for clustering of certain pairs of parents who are partnered. Older people generally did not start using public care between the first and second wave of the NKPS, so few respondents transitioned from not using public to using some form of public care. The low transition rate precludes the option of using fixed-effects models that more directly test the causal implications of our hypotheses (Johnson 2005). The random effects multilevel logistic model that we employ does not require respondents (or parents of respondents in our case) to be present at both time-points, the number of respondents will therefore not be equal across waves. The (few) differences between waves are due to older people returning to the Netherlands after 
Older adults' networks and public care receipt 1719

TA B L E 1. Descriptive characteristics (based on self-reports) of the older adult sample at two points in time

\begin{tabular}{|c|c|c|c|c|}
\hline & \multicolumn{2}{|c|}{$2002-200_{4}$} & \multicolumn{2}{|c|}{$2006-2007$} \\
\hline & Men & Women & Men & Women \\
\hline Received public care (\% yes) & 2 & 19 & 6 & 17 \\
\hline Age (years) & 70.29 & 70.49 & 73.90 & $73.9^{\circ}$ \\
\hline High education (\% yes) & $3^{6}$ & 17 & $3^{6}$ & 17 \\
\hline Intermediate education (\% yes) & 24 & 21 & 23 & 21 \\
\hline Low education ( $\%$ yes) & 40 & 62 & 41 & 62 \\
\hline Self-rated health $(0-4)$ & 0.97 & 1.24 & 1.11 & 1.27 \\
\hline Partner status (partnered =1) & 0.82 & 0.55 & 0.83 & $0.5^{\circ}$ \\
\hline Household income (log) & 7.91 & 7.60 & 7.90 & 7.60 \\
\hline Received help from adult child (\% yes) & 5 & 6 & 7 & 7 \\
\hline Received this help from daughter (\% yes) & 1 & 2 & 2 & 2 \\
\hline $\mathrm{N}$ & 232 & 259 & 231 & 259 \\
\hline
\end{tabular}

having been abroad, and attrition between waves due to migration. Although the coefficients obtained from our random effects multilevel model are a combination of cross-sectional and longitudinal coefficients (Rabe-Hesketh and Skrondal 2008), we have chosen to phrase our results as cross-sectional findings given the low transition rates mentioned above.

\section{Results}

Table 1 contains descriptive statistics of the sample based on self-reports. This first sample was used to predict the receipt of any type of public care. Table 2 describes the sample receiving public care using both self-reports and child-reports. This second sample was used to predict the receipt of unskilled types of public care versus only skilled types of public care.

In the first sample at the first time-point, 19 per cent of women and 2 per cent of men received public care. Of the older people receiving public care, $3^{2}$ per cent received unskilled forms of public care only, 26 per cent received skilled forms of public care only, while 42 per cent received both types of public care (not shown in Table 1). At the second time-point, the percentages of older adults receiving public care were quite similar. The total number of public care users in our second sample also hardly changed, $4^{14}$ at the first time-point and $4^{06}$ at the second. At the second time-point, 45 per cent received unskilled care only, 20 per cent received skilled public care only, while 34 per cent received both (Table 2, averaged over men and women). Differences between the two samples are most apparent in the age distribution of the older people. Our first sample only contained NKPS 
1720 Niels Schenk et al.

T А в L E 2. Descriptive characteristics (based on self-reports and childreports) of the older adults receiving public care at two points in time

\begin{tabular}{|c|c|c|c|c|}
\hline & \multicolumn{2}{|c|}{$2002-2004$} & \multicolumn{2}{|c|}{$2006-2007$} \\
\hline & Men & Women & Men & Women \\
\hline Received skilled care (\% yes) & 22 & 37 & 30 & $\overline{5}^{1}$ \\
\hline Received unskilled care (\% yes) & $4^{6}$ & 16 & $3^{8}$ & 13 \\
\hline Received both types of care (\% yes) & $3^{2}$ & 46 & 31 & 36 \\
\hline Age (years) & 78.00 & 76.99 & 80.87 & $7^{8.96}$ \\
\hline High education (\% yes) & 1 & 2 & 2 & 2 \\
\hline Intermediate education (\% yes) & 36 & 13 & $3^{8}$ & 13 \\
\hline Low education (\% yes) & 63 & 85 & 60 & 85 \\
\hline Partner status (partnered $=1$ ) & 0.70 & 0.52 & 0.55 & 0.37 \\
\hline Household income (log) & 7.60 & $7 \cdot 4^{\circ}$ & 7.67 & $7 \cdot 4^{\circ}$ \\
\hline Received help from adult child (\% yes) & 33 & 31 & 33 & 32 \\
\hline Received this help from daughter (\% yes) & 19 & 20 & 21 & 20 \\
\hline $\mathrm{N}$ & 132 & 282 & 125 & 281 \\
\hline
\end{tabular}

respondents; age at the first time-point was therefore limited to 79. In our second sample we also made use of linked parents from the registry and selected those who received public care. The maximum age for this sample was 99. Older people in our second sample were much less often highly educated $(2 \%)$ compared to those in the first sample ( $26 \%)$, and more often had a low education level ( $67 \%$ compared to $52 \%$ ). Older men were more often partnered compared to older women in both samples $(82 \%$ versus $55 \%$ and $70 \%$ versus $5_{2} \%$, respectively). In the first sample about 15 per cent of both older men and women had no partner (mostly because partners had died) and in the second sample $3^{\circ}$ per cent were unpartnered. The last notable difference between the two samples was the percentage of older people who received household help from the randomly selected child. In the first sample only 5 per cent of men and 6 per cent of women received such help at the first time-point. In the second sample these percentages were 33 and 31 , respectively. This difference is not surprising given that the second sample was on average considerably older and also selected on the receipt of public care.

In Table 3 we summarise our findings from the model predicting public care receipt. The number of older people who received some form of public care was rather small. Distinguishing men and women would have limited our power considerably. To check whether the model differed for men and women, we first estimated the model separately for the two groups. Only the coefficient of being partnered differed notably between men and women. We therefore included an interaction between being partnered and gender to test for the hypothesised differences between genders. Women did not 
Older adults' networks and public care receipt 1721

$\mathrm{T}_{\mathrm{AB}} \mathrm{LE}$ 3. Results from multilevel logistic regression predicting public care receipt of older adults

\begin{tabular}{lc} 
& Odds ratios for men and women \\
\hline Gender (female=1) & 2.11 \\
Partner status (partnered=1) & $0.13^{* *}$ \\
Gender $\times$ Partner status & $5.89^{* *}$ \\
Self-rated health & $2.53^{*}$ \\
Received help from adult child & 2.09 \\
Received this help from daughter & 1.29 \\
Control variables: & \\
$\quad$ Household income (log) & $0.27^{* *}$ \\
Age & $1.23^{* *}$ \\
Educational level: & 0.87 \\
$\quad$ High education & \\
$\quad$ Medium education (Ref.) & 0.98 \\
$\quad$ Low education & $-25^{\circ}$ \\
Nodel log-likelihood & 983 \\
\hline
\end{tabular}

Notes: $\mathrm{N}$ is the number of observations used in analyses, not the number of respondents. Ref.: reference category.

Significance levels: $* p<0.05$, ** $p<0.01$.

have significantly higher odds of receiving public care compared to men. The odds for men with a spouse to receive public care were almost eight times smaller compared to men without a spouse (odds ratio (OR) 0.13). For partnered women the odds of receiving public care differed much less; partnered women had only 1.3 times lower odds of receiving public care compared to women who were not partnered $(\mathrm{OR} 0.13 \times 5.89=0.77)$. This clearly shows that having a partner is a more important alternative to public care for men than for women. Findings also showed that men and women had 2.5 times higher odds of receiving public care with each unit decrease of health rating. Combining this result with our finding for partner status shows that partnered women with poor health had higher odds of receiving public care than partnered men with poor health. Household help from a randomly selected child showed no significant association with the receipt of public care, nor did receiving this help from a daughter. Income was another important determinant of public care use. With every unit increase in the log of household income, the odds of receiving public care were 3.7 times smaller, suggesting that more wealthy older people purchased market care rather than rely on public care. We did not find any significant differences between levels of education in the odds of receiving public care. Age differences did emerge, however. The odds of receiving some form of public care were 1.2 times larger with every year that men and women were older. 
1722 Niels Schenk et al.

TA B L 4 . Results from multilevel logistic regression predicting unskilled versus skilled public care receipt of older adults

\begin{tabular}{lc}
\hline & Odds ratios for men and women \\
\hline Gender (female=1) & 1.57 \\
Partner status (partnered $=1$ ) & $0.10^{* * *}$ \\
Gender $\times$ Partner status & $8.03^{* * *}$ \\
Received help from adult child & 0.66 \\
Received this help from daughter & 0.89 \\
Control variables: & \\
$\quad$ Household income (log) & $0.27^{* * *}$ \\
$\quad$ Age & 1.02 \\
$\quad$ Educational level: & \\
$\quad$ High education & 0.41 \\
$\quad$ Medium education (Ref.) & 0.92 \\
Mow education & -360 \\
N & 820 \\
\hline
\end{tabular}

Notes: $\mathrm{N}$ is the number of observations used in analyses, not the number of respondents. Ref.: reference category.

Significance levels: $* p<0.05, * * p<0.01, * * * p<0.001$.

In Table 4 we summarise the findings for our second model where we compared the receipt of unskilled public care with the receipt of skilled public care. As was the case in our first model, only the coefficient of being partnered differed notably between men and women when estimating separate models. We therefore included an interaction between being partnered and gender. Our results showed that women did not have significantly higher odds of receiving unskilled public care than men. Once older people receive some form of public care, the odds of receiving either kind of care did not differ significantly between men and women. Partnered adults had a ten times lower odds of receiving unskilled public care compared to those who were unpartnered. This clearly shows the importance of partners in decreasing the need for unskilled public care which is relatively easy to perform compared to skilled care. However, our interaction with gender shows that women hardly benefited from having a partner. The odds of receiving unskilled public care were eight times higher for partnered women compared to partnered men. Combining the odds of being partnered with the odds of the interaction shows that the odds for women with a partner to receive public care were virtually the same as for women without a partner ( 1.26 versus 1.57 , respectively). Apparently female partners were a much more important alternative to unskilled care compared to male partners. Male partners appeared to be much less of an alternative. Receiving household help from a random child made no difference in terms 
of receipt of unskilled public care. Help from a child is unimportant in rendering unskilled public care unnecessary. Our descriptive results showed that about 20 per cent of the children provided household help when the parent received public care. Apparently such help was provided irrespective of the type of public care received. Female spouses therefore seem to be the only viable alternative to public care. The odds of receiving public care did not differ significantly with levels of education. We did find, however, that with each point in the increase of log household income the odds of receiving unskilled public care were 3.7 times smaller. The odds of receiving unskilled public care did not differ by age of the respondent.

\section{Discussion}

Much of the research concerning the interface between informal and formal care does not distinguish between market- and state-provided care. This is problematic given that much of this research is sparked by interest in the expansion and later retraction of government services in elder care. In this paper we have focused on the question of whether the use of public care is restricted by the availability of informal care providers. Combining the survey data with Dutch registry data resulted in a longitudinal dataset that enabled us, contrary to most of the previous literature, to estimate models with public care as the dependent variable, and information from the survey as independent variables. With the number of older people growing increasingly large in the coming years, policy makers in many countries aim to ensure the future sustainability of elder care. Many of such attempts consist of stressing the importance of informal carers as an alternative to public care (Pavolini and Ranci 2008).

Our review of the literature resulted in specific predictions on how informal care might restrict the use of public care. Although we did not have a direct measure of informal care provided by the partner, we assumed that partnered older people in need of care would most likely receive some form of care from their partner. Our hypothesis on the importance of partners in influencing the need for public care specifically addressed the partner's gender. Our findings confirmed our hypotheses. Older people with a partner are considerably less likely to receive public care. Interestingly though, this holds especially for older men. Female partners are a much more important alternative to public care than are male partners. Scholars have often shown that women are more likely to perform the domestic tasks that should render such types of public care unnecessary (Walker, Pratt and Eddy 1995). In light of the Dutch policy measures in place, however, which 


\section{${ }_{1} 724$ Niels Schenk et al.}

require older people to first rely on the care provided by household members, one would expect male partners to play a more important role in substituting for public care than we have found. We have shown that they do not, and that to the degree that they provide care, male partners only complement public care.

The effect of having a partner on the receipt of public care was the substantial difference between men and women. We found that with deteriorating health both men and women had considerably higher odds of receiving public care, and that for older people with high levels of income the odds of receiving public care were considerably lower compared to those with low levels of income. This is not surprising given that people with high incomes pay an additional contribution when receiving public care. For older adults with higher incomes the threshold to apply for public care is therefore higher compared to older adults with lower incomes. Finally, we found that older people who received help with household tasks from a randomly selected child did not have higher odds of receiving public care compared to those who did not receive such help. Distinguishing between help received from sons or daughters did not make any difference either. Unfortunately, we only had information on household help received from up to a maximum of two randomly selected children. The absence of an association of informal care provided by children and care receipt is rather surprising given that such effects have been found in previous research (Bonsang 2009; Brandt, Haberkern and Szydlik 2009). The difference with the present research is the specific focus on public care. Bonsang (2oog) shows that care provided by children is especially an alternative for paid domestic help and not so much for (public or private) nursing care. At least in the Dutch context, where older people are not required to rely on their non co-resident adult children, care provided by children does not serve as an alternative to public care.

We hypothesised that partners and adult children, particularly if they are female, would be more likely to provide unskilled than skilled care. Our hypothesis was only partly confirmed. The odds of receiving unskilled care versus skilled care for older people with female partners were much lower compared to those with male partners. Actually, having a male partner did not lower the odds of receiving unskilled public care versus skilled care compared to having no partner. Receiving unskilled care from a random child did not lower the odds of receiving unskilled public care either. Our results therefore clearly show that female partners serve as the only actual alternative to public care, and especially so for unskilled types of care. Though the likelihood of receipt of household help from adult children and male partners is high in the Netherlands, their help does not render public care unnecessary. 
Older adults' networks and public care receipt 1725

\section{Methodological issues}

One of the drawbacks of the data we used is that the NKPS only included older people aged 79 at most. Fortunately, Statistics Netherlands has developed a parent-child module that enabled us to link children who were NKPS respondents to parents in the registers. This option provided us with a much larger number of respondents, and extended our sample to older people up to 99 years of age. Future analyses should ideally be done on older people who are the actual respondents themselves. Nevertheless, we feel confident about the quality of our data. The adult children reported on exchange behaviour which is less ambiguous and therefore less prone to measurement error than an outcome such as relationship quality (Mandemakers and Dykstra 2008). Using only primary respondents would have enabled us to measure support provided by a wider range of family members than the random child now used in the linking procedure.

Another potential source of bias lies in the random child restriction. Selecting only one child decreases the chance that ageing parents report receiving help from offspring. Especially older people with many children would actually be more likely to receive help from a child than is being picked up by the selection procedure used in the NKPS. Our results suggest, however, that even if we would find higher percentages of household help given by children to parents, there would be no difference in the estimates of public care receipt.

\section{Policy implications}

Our results have shown that in the policy setting in which our data were collected, only female partners serve as an alternative to public care. Older people in need of the types of public care discussed in this paper are only eligible for that care in case they do not have a person living in the same household who can reasonably be expected to carry out the required tasks. When potential care providers live in the household, applying for public care is only an option when the co-resident carers cannot meet the care needs. Apparently female partners are much less likely to indicate that they are overburdened by the care needs of their partners compared to male partners. Since we have studied older people aged $6_{5}$ and over, by far the largest part of our sample had left the labour market. This rules out the possibility that the differences in being overburdened are caused by differences in being employed between men and women. Another possibility might be that the processing of public care requests is gender biased. Officials might be more inclined to view female partners as being more able to provide the care needed compared to male partners. To the extent that this is true, it seems strange in light of the fact that women tend to more frequently use health 


\section{Niels Schenk et al.}

services and have higher morbidity (Verbrugge 1989). Perhaps favouring male partners is partly due to the age differences between partners. Men are on average older than their female partners, which offsets the overall gender differences found in health service use and morbidity. Unfortunately we were not able to control for the health of the partner, or the age difference between partners.

Future work should try to find out whether female partners actually suffer fewer encumbrances, or whether other processes such as a possible gender bias are responsible for the lower proportions of older partnered men who receive public care compared to older partnered women. Our results suggest that part of the difference between genders in receiving public care is attributable to the (perceived) lack of care-giving skills of male partners as alternative to public care. Much might be gained in terms of public care costs by addressing the possible gender bias in processing public care requests. Another option might be that male partners are trained in, or being convinced of, their skills to care for their spouse, at least in cases where their own health is not the limiting factor (Van den Broek 2013). A greater reliance on male partners is called for given the expected trends in living arrangements

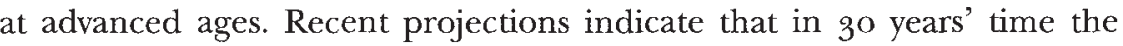
proportion of women living with a partner will sharply increase, whereas the proportion of men who are part of a couple will remain relatively unchanged (Gaymu, Ekamper and Beets 2008).

\section{Generalisation beyond the Netherlands}

Population ageing is visible in most of the western world. Since the data we used are limited to the Netherlands only, it remains unclear to what degree our results can be generalised to other western countries. There are as many policy measures as there are countries, and our results are for a large part determined by these measures. Moreover, not many elder care policies are as generous as the Dutch (Saraceno and Keck 2008). In countries with less generous policy arrangements, informal care by family members other than the (female) partner plays a role in substituting for public care. Tomassini et al. (2004) have, for example, shown that in countries such as Italy, where public care policies are much less generous compared to the Netherlands, older women are much more likely to live with their children.

\section{Acknowledgements}

The Netherlands Kinship Panel Study is funded by grant $480-10-009$ from the Major Investments Fund of the Netherlands Organization for Scientific Research (NWO), and by the Netherlands Interdisciplinary Demographic Institute (NIDI), 
Utrecht University, University of Amsterdam and Tilburg University. This research was partly supported by a grant from InstituutGak. We thank Thijs van den Broek for his help with describing the Exceptional Medical Expenses Act.

\section{References}

Andersen, R. M. 1995. Revisiting the behavioral model and access to medical care: does it matter? Joumal of Health and Social Behatior, 36, 1, 1-10.

Arber, S. and Ginn, J. 1995. Gender differences in informal caring. Health and Social Care in the Community, 3, 1, 19-31.

Bolin, K. Lindgren, B. and Lundborg, P. 2008. Informal and formal care among single-living elderly in Europe. Health Economics, 17, 3, 393-409.

Bonsang, E. 2009. Does informal care from children to their elderly parents substitute for formal care in Europe? Journal of Health Economics, 28, 1, 143-54.

Brandt, M., Haberkern, K. and Szydlik, M. 2oog. Intergenerational help and care in Europe. European Sociological Review, 25, 5, 585-601.

Campbell, L.D. and Martin-Matthews, A. 2003. The gendered nature of men's filial care. Joumals of Gerontology: Psychological Sciences and Social Sciences, 58B, 6, $35^{\circ}-8$.

Centrum Indicatiestelling Zorg (CIZ) 201 2. CIZ indicatiewijzer versie 5.o. Toelichting op de Beleidsregels Indicatiestelling AWBZ $20 \mathrm{I} 2$ zoals vastgesteld door het ministerie van VWS. CIZ, Driebergen, The Netherlands.

Da Roit, B. 2012. The Netherlands: the struggle between universalism and cost containment. Health and Social Care in the Community, 2o, 3, 228-37.

Daatland, S. and Lowenstein, A. 2005. Intergenerational solidarity and the family-welfare state balance. European Journal of Ageing, 2, 3, 174-82.

De Leeuw, E. D. and De Heer, W. 2001. Survey nonresponse. In Groves, R. M., Dillman, D.A., Eltinge, J. L. and Little, R.J.A. (eds), Trends in Household Survey Nonresponse: A Longitudinal and International Comparison. Wiley, New York, $4^{1-54}$.

Dykstra, P. A., Kalmijn, M., Knijn, T. C. M., Komter, A. E., Liefbroer, A. C. and Mulder, C. H. 2005. Codebook of the Netherlands Kinship Panel Study, a Multi-actor, Multi-method Panel Study on Solidarily in Family Relationships, Wave I. Netherlands Interdisciplinary Demographic Institute, The Hague.

Esping-Andersen, G. 1990. The Three Worlds of Welfare Capitalism. Polity Press, Cambridge.

European Commission 2012. The 2012 Ageing Report: Economic and Budgetary Projections for the ${ }_{2} 7$ EUMember States (2010-2060). European Commission, Brussels.

Eurostat 2012. Europop. Available online at http://epp.eurostat.ec.europa.eu/ portal/page/portal/population/data/database [Accessed 11 July 2012 ].

Gaymu, J., Ekamper, P. and Beets, G. 2008. Future trends in health and marital status: effects on the structure of living arrangements of older Europeans in 2030. European Journal of Ageing, 5, 1, 5-17.

Geerts, J. 2012. Determinants of use of formal and informal personal care by older persons living at home: evidence from Germany, the Netherlands and Spain. In Geerts, J., Willemé, P. and Mot, E. (eds), Long-term Care Use and Supply in Europe: Projections for Germany, The Netherlands, Spain and Poland. ENEPRI Research Report No. 116 , CEPS, Brussels, 15 -29.

Haberkern, K. and Szydklik, M. 2010. State care provision, societal opinion and children's care of older parents in 1 I European countries. Ageing $\mathcal{F}^{2}$ Sociely, 30, 2, 299-323. 
1728 Niels Schenk et al.

Johnson, D. 2005. Two-wave panel analysis: comparing statistical methods for studying the effects of transitions. Jourmal of Marriage and Family, 67, 4, $1061-75$

Katz, S.J., Kabeto, M. and Langa, K. M. 20oo. Gender disparities in the receipt of home care for elderly people with disability in the United States. JAMA: Joumal of the American Medical Association, 284, 23, 3022-7.

Knijn, T. and Kremer, M. 1997. Gender and the caring dimension of welfare states: toward inclusive citizenship. Social Politics: International Studies in Gender, State, Society, 4, 3, 328-61.

Kremer, M. 2oo6. Consumers in charge of care: the Dutch personal budget and its impact on the market, professionals and the family. European Societies, 8, 3, $385-401$.

Li, L. W. 2005. Longitudinal changes in the amount of informal care among publicly paid home care recipients. The Gerontologist, $45,4,465-73$.

Litwak, E. 1985 . Helping the Elderly: The Complementary Roles of Informal Networks and Formal Systems. Guilford Press, New York.

Mandemakers, J.J. and Dykstra, P.A. 2008. Discrepancies in parent's and adult child's reports of support and contact. Joumal of Marriage and Family, 7o, 2, $495^{-5} 5^{\circ 6 .}$

Mol, E. 2010. The Dutch System of Long Term Care. CPB Document No. 204, CPB Netherlands Bureau for Economic Policy Analysis, The Hague.

Motel-Klingebiel, A., Tesch-Römer, C. and Von Kondratowitz, H. 2005. Welfare states do not crowd out the family: evidence for mixed responsibility from comparative analyses. Ageing $\mathcal{E}$ Society, 25, 6, 863-82.

Noël-Miller, C. M. 2010. Longitudinal changes in disabled husbands' and wives' receipt of care. The Gerontologist, 50, 5, 681-93.

Organisation for Economic Co-operation and Development 2005. Long-term Care for Older People. Organisation for Economic Co-operation and Development, Paris.

Pavolini, E. and Ranci, C. 2008. Restructuring the welfare state: reforms in long-term care in Western European countries. Journal of European Social Policy, $18,3,24^{6-59}$

Rabe-Hesketh, S. and Skrondal, A. 2oo8. Multilevel and Longitudinal Modeling Using Stata. Stata Corp, College Station, Texas.

Saraceno, C. and Keck, W. 2008. The Institutional Framework of Intergenerational Family Obligations in Europe: A Conceptual and Methodological Overview. Wissenschaftszentrum Berlin für Sozialforschung, Berlin.

Stoller, E. P. and Cutler, S. J. 1992. The impact of gender on configurations of care among married elderly couples. Research on Aging, 14, 3, 313-30.

Sundström, G., Malmberg, B. and Johansson, L. 2006. Balancing family and state care: neither, either or both? The case of Sweden. Ageing $\mathcal{F}^{2}$ Society, 26, $5,767-82$.

Tomassini, C., Glaser, K., Wolf, D. A., Broese van Groenou, M. I. and Grundy, E. 2004. Living arrangements among older people: an overview of trends in Europe and the USA. Population Trends, $115,34,24-34$.

Tuynman, M. and Marangos, A. M. 2010. Gemeentelijk Wmo-beleid op de negen prestatievelden. In de Klerk, M., Gilsing, R. and Timmermans, J. (eds), Op weg met de Wmo. SCP The Netherlands Institute for Social Research, The Hague, $69-100$.

Van den Broek, T. 2013. Formalization of informal care in the Netherlands: cost containment or gendered cost redistribution? International Joumal of Feminist Approaches to Bioethics, 6, 2. 
Older adults' networks and public care receipt 1729

Van Hooren, F. and Becker, U. 2012. One welfare state, two care regimes: understanding developments in child and elderly care policies in the Netherlands. Social Policy $\mathcal{E}^{2}$ Administration, 46, 1, 83-107.

Van Houtven, C. H. and Norton, E. C. 2004. Informal care and health care use of older adults. Journal of Health Economics, 23, 6, $1159-80$.

Verbrugge, L. M. 1989 . The twain meet: empirical explanations of sex differences in health and mortality. Journal of Health and Social Behavior, 30, 3, 282-304.

Walker, A.J., Pratt, C. C. and Eddy, L. 1995. Informal caregiving to aging family members: a critical review. Family Relations, 44, 4, 402-1 I.

Wolff, J.L. and Kasper, J. D. 2006. Caregivers of frail elders: updating a national profile. The Gerontologist, 46, 3, 344-56.

Accepted I2 June 2oI3; frrst published online 24 July 2013

Address for correspondence:

Niels Schenk, Department of Sociology,

Erasmus University, P.O. Box $173^{8}$,

Rotterdam 3000 DR, The Netherlands.

E-mail: n.schenk@fsw.eur.nl 